\title{
Optimization and Simulation for E-Commerce Supply Chain in the Internet of Things Environment
}

\author{
Liwei Zhu \\ College of Commerce, Guangdong Polytechnic of Science and Technology, Zhuhai 519090, China \\ Correspondence should be addressed to Liwei Zhu; 11630019@zju.edu.cn
}

Received 12 August 2020; Revised 5 October 2020; Accepted 8 October 2020; Published 19 October 2020

Academic Editor: Zhihan Lv

Copyright $\odot 2020$ Liwei Zhu. This is an open access article distributed under the Creative Commons Attribution License, which permits unrestricted use, distribution, and reproduction in any medium, provided the original work is properly cited.

\begin{abstract}
The supply chain optimization of e-commerce is the optimization of the integrated linear management model for e-commerce enterprises based on manufacturers, suppliers, warehouses, distribution centers, and channels. The application of Internet of Things (IoT) technology to the optimization of e-commerce supply chain can help e-commerce enterprises to monitor each product in real time and manage logistics system reasonably; thus, the circulation process of e-commerce product in the supply chain can be monitored and shared, and the product information at each stage of the supply chain can be analyzed and predicted, helping e-commerce companies to estimate the future trends or accident probability. On the analysis of summarizing and analyzing previous works, this article expounded the research status and significance of e-commerce supply chain optimization, elaborated the development background, current status, and future challenges of the IoT technology, introduced the methods and principles of the node distribution model and constraint parameter analysis of logistics supply chain, constructed the IoT-based e-commerce supply chain linear and nonlinear model including competition and risk-control modules, performed the design of IoT-based e-commerce supply chain optimization, and discussed the solutions to procurement robustness optimization and management process optimization. The final simulation analysis showed that the proposed optimization model can effectively predict e-commerce product information in each stage of the supply chain; the IoT-based e-commerce supply chain optimization can enable each node company in the supply chain to improve the quality of information transmission and reduce the risk of information asymmetry in the process of e-commerce exchanges and can quickly and easily respond to the sudden changes of market and environment, thereby promoting them to cooperate with each other for establishing a supply chain network structure with closer business relationships, smoother logistics transportation, more reasonable benefit sharing, and stronger market competitiveness.
\end{abstract}

\section{Introduction}

Internet of Things (IoT) is such an information-based and intelligent network that utilizes the communication technologies such as Internet to connect sensors, people, and things in a new way to form a connection. Through direct communication between things, the time taken for the entire transfer process is shortened, and the operation efficiency of the entire supply chain is improved so as to achieve the realtime tracking, monitoring, and management in a real sense [1]. The IoT is composed of three parts of sensor network, transmission network, and application network, including four key technologies of radio frequency identification, sensors, cloud computing, and network communication.
The rapid developments and industry applications of the IoT have brought huge opportunities to deepen the development of e-commerce [2]. The application of related technologies and methods in the field of e-commerce will help promote the rapid and healthy development of e-commerce. For example, in the aspect of product management, the use of IoT technology to establish a real-time tracking system for products can enable enterprises to monitor the status of products at any time and effectively manage the quality of the products [3]. The IoT provides an effective information technology support platform for the integration of information and resources in the e-commerce supply chain, tracking, and monitoring of the entire product life cycle. However, consumers still feel insecure about e-commerce 
psychologically due to various shortcomings in e-commerce logistics, so it is necessary to study the optimization of the IoT-based e-commerce supply chain [4].

The application of IoT to the e-commerce supply chain optimization can help the e-commerce companies to monitor each product in real time and optimize the management of the logistics system, which can not only supervise and circulate products in the supply chain but also share related information [5]. The e-commerce supply chain information integration and sharing platform can achieve unified standards for internal and external information, interoperable, seamless docking, integration, analysis, and sharing so that each node company in the supply chain can perceive information in a short time. It can analyze and forecast the information of products at various stages of the supply chain, help e-commerce companies to estimate future trends or the probability of accidents, so as to take timely remedial measures or early warnings, greatly improve the ability of e-commerce companies to respond to the market, and improve business management capabilities traditional logistics is mostly confined within the enterprise [6]. With information flow as the control object and the main enterprise as the core, the entire logistics system is controlled from the supply source to the demand source [7]. The e-commerce supply chain is an optimization of integrated linear management models based on manufacturers, suppliers, warehouses, distribution centers, and channels, which includes the optimization of five main related links of production, distribution, and retailing in the context of increasingly sophisticated transportation and warehousing, global division of labor, and corporate transnational and cross-regional operations [8].

On the analysis of summarizing and analyzing previous works, this article expounded the research status and significance of e-commerce supply chain optimization, elaborated the development background, current status, and future challenges of the IoT technology, introduced the methods and principles of the node distribution model and constraint parameter analysis of logistics supply chain, constructed an IoT-based e-commerce supply chain linear and nonlinear model including competition and risk-control modules, performed the design of IoT-based e-commerce supply chain optimization, and discussed the solutions to procurement robustness optimization and management process optimization. The study results of this paper provide a certain reference for further research studies on the e-commerce supply chain optimization in the IoT environment. The detailed chapter arrangement is as follows. Section 2 introduces the methods and principles of the node distribution model and constraint parameter analysis of logistics supply chain; Section 3 establishes an IoT-based e-commerce supply chain model including competition and risk-control modules; Section 4 performs the optimization design of IoT-based e-commerce supply chain and discusses the optimization solutions to procurement robustness and management process; Section 5 performs a simulation experiment and its analysis; Section 6 provides conclusion.

\section{Methods and Principles}

2.1. Node Distribution Model of Logistics Supply Chain. The e-commerce supply chain is characterized by the complexity and dynamics of the supply chain itself, and the data and models used in supply chain optimization should also meet the dynamic characteristics [9]. Considering the disturbing effect of the dynamic environment on the supply chain node distribution, the optimized node distribution function is constructed as follows:

$$
\frac{\partial \varphi(x)}{\partial x}=\frac{1}{k} \cdot \frac{\partial^{2}}{\partial x^{2}}[M(x) \cdot \varphi(x)]+\frac{1}{r} \cdot \frac{\partial}{\partial x}[M(x) \cdot \varphi(x)],
$$

where $M(x)$ is the average trend of measuring the optimization level of supply chain $\varphi(t) ; k$ is the coefficient of supply chain risk-control ability; $r$ is the coefficient of diffusion and convergence of supply chain optimization.

It is assumed that there is no shortage of e-commerce product supplies in the upstream and meets the abovementioned optimization node distribution function, and then the maximum profit function that the upstream supplier may achieve is as follows:

$$
M_{x}\left(p_{x}, q_{x}\right)=\left(p_{x}-k\right) \cdot q_{x}^{2}-k\left(\frac{1}{\alpha} \cdot q_{x}-k\right) p_{x}^{2},
$$

where $p_{x}$ is the cost bonus coefficient in the IoT environment; $q_{x}$ is the output matching coefficient in the IoT environment; $\alpha$ is the profit loss caused by information asymmetry in the entire e-commerce supply chain.

When the distribution of nodes such as manufacturers and retailers in the e-commerce supply chain shares real data, both parties can get a higher net income increase and at the same time bear the risk of data being leaked by each other, so the profit function of the two can be expressed as follows:

$$
\begin{gathered}
M_{x}\left[p_{x}, \varphi(x)\right]=w \cdot Q \cdot \varphi(x)^{2}-c[\varphi(x)+P] p_{x}^{2}, \\
M_{x}[p(x), \varphi(x)]=\rho_{R} \cdot Q \cdot \varphi(x)^{2}-E_{M}[\varphi(x)+P] p(x)^{2},
\end{gathered}
$$

where $w$ is the order price; $c$ is the unit cost, $Q$ is the market demand, $P$ is the market price of the product, $E_{M}$ is the estimated value of the single-cycle shared data, and $\rho_{R}$ is the probability of leaking shared data.

When the distribution of the nodes of the logistics supply chain does not affect each other, the standard deviation of the aggregate industry demand is less than the sum of the standard deviations $(\sigma)$ of the individual regional requirements, indicating that the aggregate effect can reduce the fluctuation of demand to achieve the purpose of reducing safety stocks. At this time, the aggregate demand is normally distributed:

$$
\sigma=\sqrt{\varphi(x)^{2} \cdot s_{i}^{2}+\frac{1}{\rho} \cdot S_{i} \cdot \operatorname{cov}(i, j)-R[\varphi(x)+P] p_{x}^{2}},
$$


where $S_{i}$ is the company's expected value of the market demand in each period, $\operatorname{cov}(i, j)$ is the company's covariance of the market demand in each period, and $R$ is the average level of the periodic service. Such enterprises do not participate in actual production and require less investment in infrastructure but have high requirements on management and planning.

\subsection{Constraint Parameter Analysis of Logistics Supply Chain.} The degree of information processing in the e-commerce supply chain can be obtained by using the ratio of the number of times the information is automatically processed in each circulation link of the supply chain to the total number of information processing times and then multiplying them by the importance of each supply chain link to obtain the following [10]:

$$
E_{i}=\sum_{j=1}^{n}\left[\frac{1}{\rho} \cdot \frac{X_{i}}{Y_{i}}+r_{i j} \cdot E_{M}[\varphi(x)+P] p(x)^{2}\right]^{2},
$$

where $X_{i}$ is the number of times that information is automatically processed on the $i$-th supply chain node; $Y_{i}$ is the total number of times that information is processed on the $i$ th supply chain node; $r_{i j}$ is a weighted value that is the importance of the information automation of the $i$-th node company to the entire supply chain.

It is supposed that there are $n$ optimization processes in an e-commerce supply chain. Let $X=\left(x_{1}, x_{2}, \ldots, x_{n}\right)(i=1$, $2, \ldots, n)$, and each process is represented by $m$ indicator sets. The optimization process $x_{i}$ is measured by attributes, and its attribute value $a_{i j}$ is obtained from the actual situation so as to form a decision matrix $A=\left(a_{i j}\right)_{n \times m}$ :

$$
A=\left[\begin{array}{cccc}
a_{11} & a_{12} & \cdots & a_{1 m} \\
a_{21} & a_{22} & \cdots & a_{2 m} \\
\vdots & \vdots & \vdots & \vdots \\
a_{n 1} & a_{n 2} & \cdots & a_{n m}
\end{array}\right],
$$

where $n$ is the number of rows in the optimization matrix, $i$ is the number of optimizations for a particular process, and $k$ is a criterion. If $r_{i k}$ represents the optimization level of process $i$ under criterion $k$, the ordinal value of the optimization number $i$ can be given by

$$
O_{i}=\sum_{k=1}^{n} \sum_{i=1}^{n}\left(n-r_{i k}\right)
$$

It assumed that the revenue function of the upstream supplier is $W_{i}\left(s_{i}, q_{i}\right)$, where $s_{i}$ is the sales price of the supplier and $q_{i}$ is the sales volume of the supplier; $Q_{i}$ is a single item. The cost of selling products and the indestructible constraint parameter function of the upstream supplier is given by

$$
W_{i}\left(s_{i}, q_{i}\right)=\left(s_{i}-Q_{i}\right) q_{i} .
$$

The core company's demand in each period follows a normal distribution with an average value of $m$; each supply interval period is $L$, so the demand in the $L$ period also follows a normal distribution with an average value of $L_{m}$ of target inventory holding $N$ is as follows:

$$
N=\left(L Q_{i}\right)^{1 / 2}\left(\frac{P-C}{P-H}\right)+L_{m}-W_{i}\left(s_{i}, q_{i}\right),
$$

where $P$ is the price provided by the supplier management enterprise to the core enterprise, $C$ is the unit production cost, and $H$ is the unit inventory holding cost. When the supplier management company cannot meet the inventory requirements due to some force majeure, the company can only go to resource pool for assistance.

\section{IoT-Based E-Commerce Supply Chain Model}

3.1. Competition Model of E-Commerce Supply Chain. In the traditional model, there are information barriers between logistics providers and they rely on information barriers to obtain competitiveness due to the immature information sharing mechanism and technology. But the IoT brings technical support for information sharing. In this context, the reasonable requirements for the disclosure of noncommercial confidential basic information such as distribution customers, channels, and partners of all logistics suppliers have been realized, and they have not obeyed the market because of the market's need for higher quality and lower cost logistics services. In the distribution and retail links in the linear and nonlinear supply chain optimization models, it is also convenient to monitor the inventory in real time, grasp the detailed information of the goods, improve the level of automation and mechanization of inventory and distribution, and realize a highly modernized logistics operation. Under the construction of the entire IoT architecture, this involves the specification of logistics information representation, the standardization of interfaces between different links, and the input and processing of output file formats from identification tags to label reading devices to transmission and processing [11]. This is beneficial to the information exchange infrastructure between different e-commerce supply chain member companies or different logistics subsystems and to build the largest information platform for information exchange between different individuals, of which the logistics industry is the biggest beneficiary.

The main risks faced by the e-commerce supply chain in the IoT environment are information security risks, reputation risks, and distribution risks in the linear and nonlinear supply chain optimization models. Due to the complexity and diversity of the e-commerce supply chain risk itself, it also requires higher risk assessment methods. Therefore, the selected risk assessment method must be able to deal with some unknown, large fluctuations and cause large losses, and it can give a more accurate assessment of the risks. The framework of the IoT-based e-commerce supply chain model is shown in Figure 1. For supply chain managers, it is necessary to determine the conditions under which the supply chain needs to be adjusted and optimized in order to reduce the maintenance cost of the supply chain while improving the value of the entire supply chain. A complete supply chain will always develop in two directions. First, the 

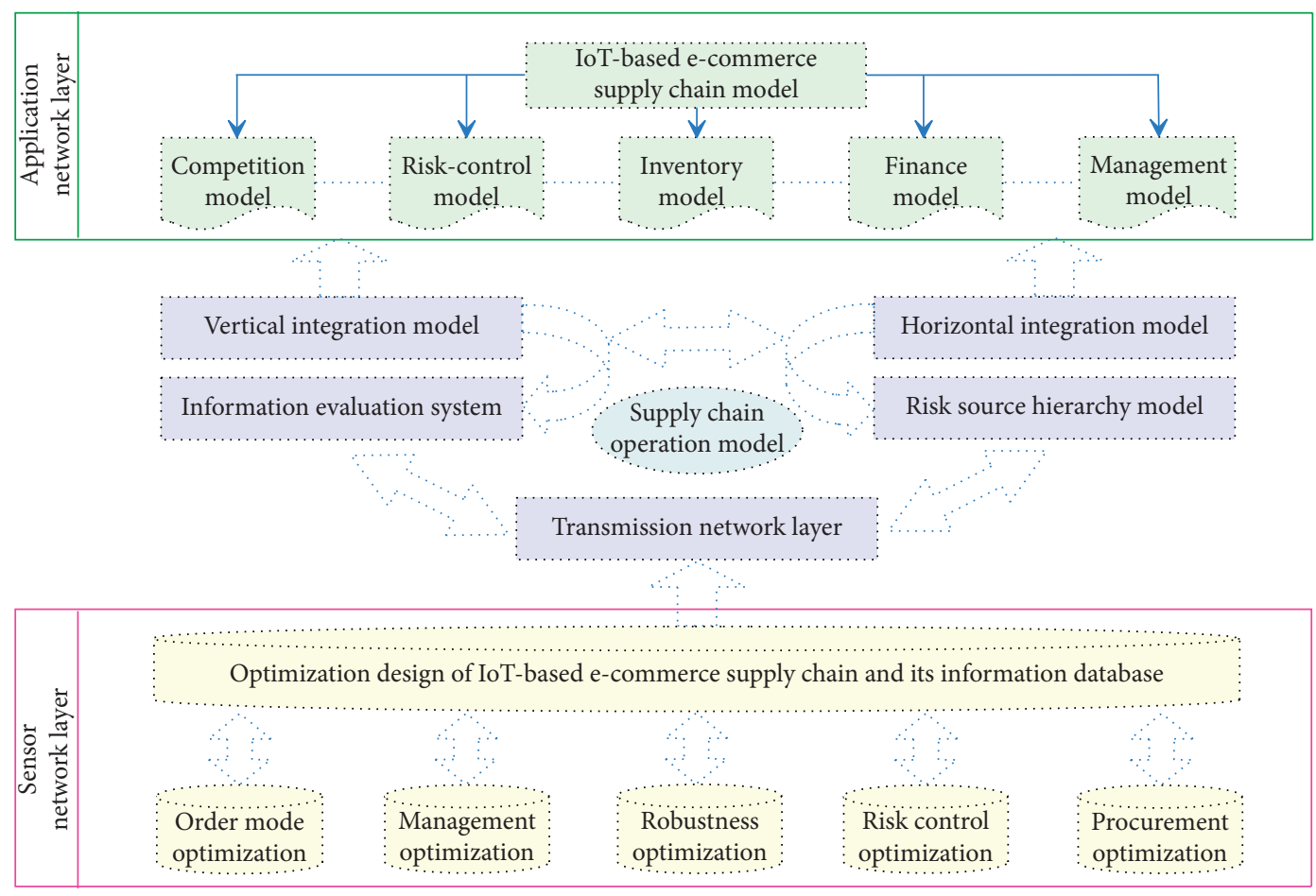

FIGURE 1: Framework of the IoT-based e-commerce supply chain model.

supply chain risks can converge well, and the influence of the supply chain risk factors on each other is reduced to the lowest level at a certain level of risk, and the supply chain maintains stable operation at a certain level of risk through effective management and control of the manager. Second, the supply chain manager's ability to manage supply chain risks is low, causing the supply chain risk level to exceed a critical value, and the supply chain risk cannot effectively converge. The mutual influence of factors is further strengthened, making the risks continue to spread, eventually leading to the collapse of the supply chain [12].

The closed-loop operation mode in the e-commerce supply chain includes the forward supply chain activities of new products from raw materials to consumers, the return of waste products from end users to producers, and the conversion of waste products into remanufactured products by producer activities, product redesign activities for reuse of waste products, environmental monitoring of raw materials, new products, waste products, and green logistics management. Ensuring the accuracy and timeliness of information is the key factor for the success of the closed-loop operation mode of the linear and nonlinear optimization models. The rise of the IoT has provided good development opportunities for its operation and management. Through the IoT platform, all companies in the closed-loop supply chain are connected to form an end-to-end intelligent supply chain logistics distribution service process, which can achieve accurate and effective collaborative distribution based on the real-time status of logistics distribution [13]. The IoT provides an effective information technology support platform for the integration of information and resources in the e-commerce supply chain, tracking and monitoring of the entire product life cycle. The closed-loop supply chain operation system based on the IoT can implement real-time tracking and supervision of the production, distribution, retail, and recycling of products in the supply chain, enhance management transparency, and enable companies in the e-commerce supply chain to respond quickly to the market demand, improve service levels, and enhance corporate competitiveness.

\subsection{Risk-Control Model of E-Commerce Supply Chain.} Because many small-volume orders in the traditional supply chain are difficult to access to the factory's mass production plan and subsequent shipment clearance is more troublesome, cross-border e-commerce has provided the possibility to solve these problems. Centralized processing of small orders enables exporters to place orders and produce uniformly, making it easy for factories to adjust product and profit structure. In recent years, as the minimum order quantity is not high, many customers have expressed difficulties in finding good suppliers. Some buyers prefer a supplier with poor quality but a low minimum order quantity, rather than a supplier with a high minimum order quantity but a high quality. Since consumers are not limited by time and space on the e-commerce platform and can browse the information of the products they are interested in, exporters need to pay more attention to the front end of the linear and nonlinear optimization models, actively develop and design products, and improve product quality to attract consumers' attention. The high-quality shops on the online platform will have a higher visibility than the products on the offline exhibition. Large exporters also need 
to build brands, promote their brands on cross-border e-commerce platforms, expand product awareness and influence, and establish cross-border e-commerce operations teams to make every node on the line such as customs clearance and logistics. It gives full play to its own offline supply chain mature advantages, thereby forming an integrated advantage of online transactions. Figure 2 shows the relative optimization contribution rate of different optimization terms in the IoT-based e-commerce supply chain model.

The integration of intelligent sensing equipment and the Internet has optimized the basic links of e-commerce supply chain inventory management. The traditional method of manually recording financial data information has lagged behind and cannot match the current market development environment and technology level. For example, the quantitative assessment benchmark is established through corresponding index data. Before the related inventory management model is reformed, the product quality and service levels are difficult to quantify [14]. The integration of the IoT and Internet technologies can establish a sensor network, reduce costs to a certain extent, perform timely distribution, track real-time e-commerce products, reduce the risk of disputes between enterprises and consumers, and protect consumers' basic rights and interests. They improve the service level of the enterprise and increase customer satisfaction, and the e-commerce companies should use empirical data as the basic basis and make corresponding basic management decisions. For example, they should focus on capital investment, sort out changes in market demand, and provide customers with basic value-added services. As a method of supply chain inventory management reform, the use of quantification as an assessment standard is the basic sign of management progress for e-commerce enterprises, and it can be used as a reference for enterprise data demonstration and management reform.

Supply chain finance is a process of systematically optimizing the availability and cost of funds in a corporate ecosystem dominated by core companies. When the sensor of the IoT detects the risk of qualitative changes in the collateral, it timely sends a signal to the information management system and notifies the customer, which facilitates the bank to quickly determine the condition of the collateral and decide whether to recheck the price and compensate for the decline. If the total price drop exceeds the bank's minimum credit line and the borrower has not added pledges or provided new guarantees, immediately announce that the credits will expire prematurely. After communicating with customers, take measures such as auctions to sell pledges and repay loans. Through radio frequency identification technology, the e-commerce and banks can clearly understand and grasp every link of collateral from production and transportation to sales in the linear and nonlinear optimization models. The readers installed in factories, distribution centers, and logistics supervision warehouses can automatically record items throughout the supply of the flow of the chain. From the perspective of the entire integrated supply chain, the transparency of the supply chain and the accuracy of the information will be maximized, which is exactly the problem of difficult supervision of banks. After the bank has reached a transaction with the on-chain enterprise, the bank delivers the collateral from the enterprise to the cooperative warehouse. The warehouse is responsible for keeping the collateral and regularly checks the value of the collateral with the bank [15].

\section{Optimization Design of IoT-Based E-Commerce Supply Chain}

4.1. Procurement Robustness Optimization of E-Commerce Supply Chain. With the support of IoT technology and the e-commerce procurement link, in order to achieve longterm mutual benefit and close cooperation of information sharing among members of the supply chain, it is necessary to continuously improve the management level of suppliers and support a series of supplier management activities. The perfect management system integrates powerful IoT technology, which can produce comprehensive data such as quantity, quality, price, cost, delivery efficiency, and service level and can provide the supplier's supply performance, supply capacity, supply reputation, and technical level. The management efficiency and other indicators better streamline and optimize suppliers and ensure the quality of supply chain procurement [16]. The e-commerce procurement logistics system includes many logistics activities, such as packaging, loading, unloading, transportation, warehousing, handling, and information management from suppliers to producers, and it is an important part of the robust optimization of supply chain procurement (Figure 3 ). The packaging and transportation links, storage inspection links, and material warehousing links of the e-commerce procurement logistics system need to be fully optimized in accordance with the new IoT environment. Through a comprehensive perception of raw materials, perfecting transportation plans, optimizing logistics routes, and improving procurement models, the scientific management of raw materials storage warehouses, delivery vehicles, and transportation routes is completed to realize flexible and agile procurement.

Delivery management under traditional supply chain management often becomes the last link that affects the overall efficiency of supply chain enterprises. Uncertain transportation information, poor timeliness, and high cargo damage rates are the direct causes of customer satisfaction decline. In e-commerce platforms, on the other hand, upstream companies in the supply chain can release logistics and transportation information in a timely manner to provide downstream companies and consumers with the convenience of querying and tracking. In addition, they can adjust delivery batches or delivery times in a timely manner when market sales conditions change, increasing the number of delivery companies and time flexibility and reducing the risk of corporate material reserves. The enterprise can reasonably arrange the production plan of the product according to the sales situation of the e-commerce platform and can adjust the production capacity and product structure in a timely manner based on the analysis of the data 


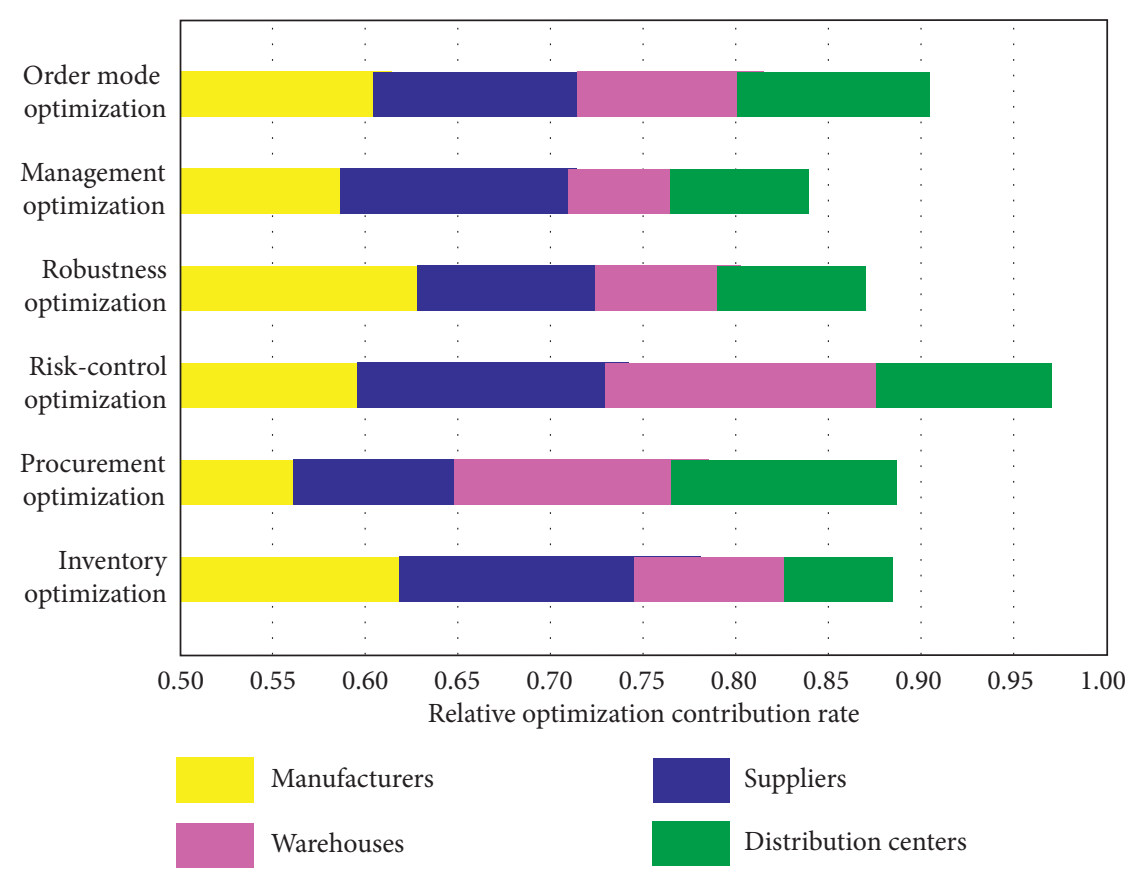

FIGURE 2: Relative optimization contribution rate of different optimization terms in the IoT-based e-commerce supply chain model.

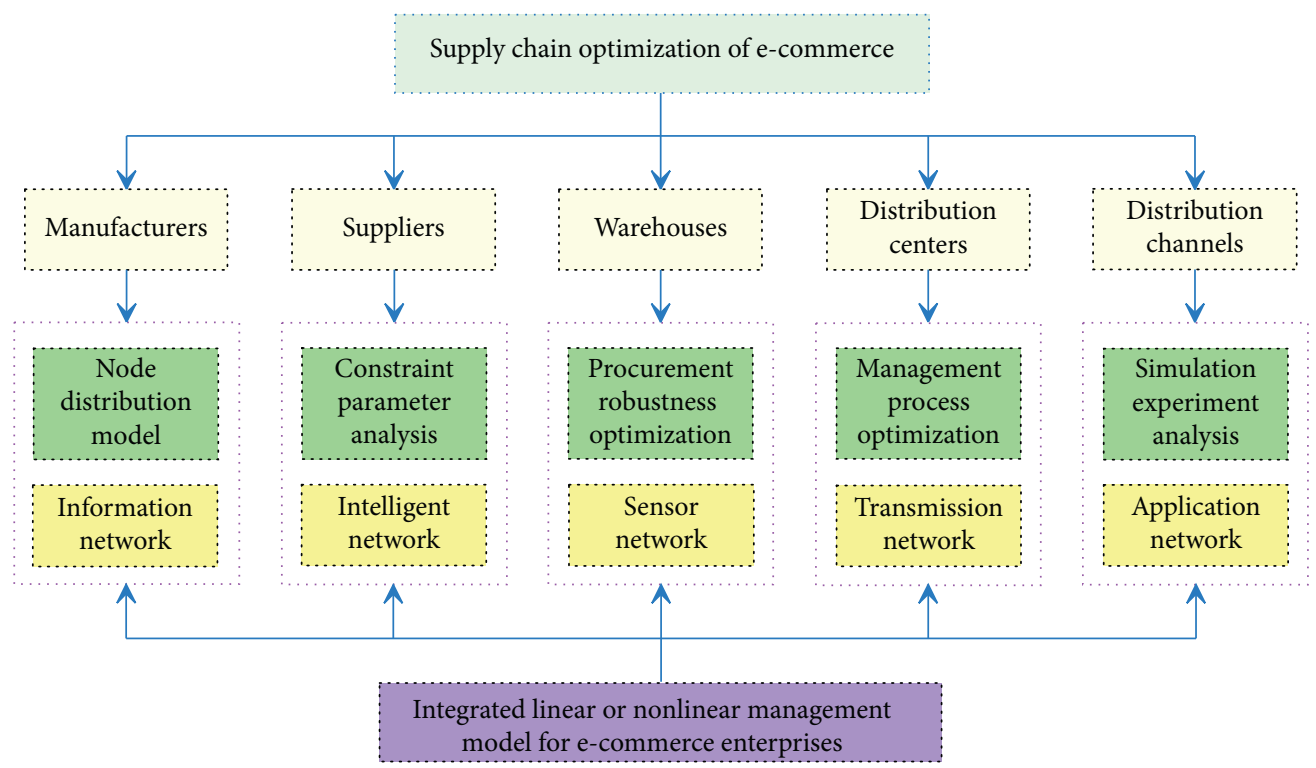

Figure 3: Optimization design for IoT-based e-commerce supply chain.

transmitted by the ordering system to further reduce the uncertain factors in production. Through the timely and rapid update of information and integrated processing, it can achieve collaborative management of production and sales, shorten the manufacturing cycle, reduce customer waiting time, and improve customer satisfaction. In terms of delivery and delivery time, real-time query of delivery information allows customers to reasonably arrange the delivery time and ensures the timely supply of goods in the linear and nonlinear optimization models. The customers can also log in to the enterprise's e-commerce platform to query product update information in real time in order to carry out material procurement planning and inventory planning adjustment, and realize flexible procurement at any time.

Under the support of IoT technology, the connection between e-commerce companies has shown a networked and cross-shaped development. The network's corporate layout will provide a larger financial services industry including banks market space. In addition, the IoT will be used to achieve efficient resource allocation and information sharing, especially the IoT itself, in many areas of e-commerce product research and development and production processes, due to the cross and openness of the network. 
With the further promotion and extension of the IoT in various fields such as social production, there will be applications of IoT technologies in everything from raw material production to product quality and logistics distribution. The services provided by this supply chain finance are no longer targeted at a specific customer but are based on the overall situation of the entire IoT system to formulate corresponding development strategies and countermeasures in the linear and nonlinear optimization models. Because the market is constantly changing and developing, only from a global perspective, we can avoid making wrong decisions due to unscientific analysis, which ultimately affect the vital interests of the financial services industry and its customers. Only constructing a three-dimensional and multidimensional IoT platform from the scope and degree will lay a solid technical foundation for the future development of e-commerce supply chain finance [17].

\subsection{Optimization of E-Commerce Supply Chain Management} Process. The supply chain management mode under the e-commerce environment information flow management, capital flow management, and logistics management constitutes the three major parts of supply chain management. The enterprises in the supply chain should consider the various business transactions within the enterprise and with the nodes in the supply chain as an overall functional process. By effectively and transparently coordinating the information flow, capital flow, and logistics in the supply chain, the internal supply chain of the enterprise integrated management with the supply chain outside the enterprise to form an integrated supply chain management system. Because the core enterprises of e-commerce and the upstream suppliers, downstream end customers, banks, and logistics centers can exchange information quickly through the Internet, at the same time, the nodes in the supply chain can also communicate with each other. The IoT-based node distribution of the logistics supply chain with horizontal and vertical integration modes is shown in Figure 4. They overthrow the traditional model and effectively connect the islands of each business node in the supply chain to achieve true business information integration and sharing through the application of e-commerce. At the transaction stage, the business needs to further improve the logistics management link, minimize the time required for logistics in the supply chain, and achieve unified and synchronized logistics management with information flow and capital flow management, thereby establishing a truly powerful and fast response of the supply chain management system.

The IoT technology enables tracking of items flowing in the e-commerce supply chain, and at the same time, it can transmit data to all participants in real time, reducing the phenomenon of information distortion. Fast information transmission speed can greatly reduce the cost of transmission time between roles such as enterprises, merchants, and users. With the development of globalization and the improvement of people's living standards, the demand for personalized customization is getting higher and higher, and the e-commerce platform has turned to a user-oriented personalized design concept [18]. Each part of the e-commerce supply chain can be associated with users through the network to obtain a wider and more effective interaction and production scheme, so the platform more respects the individual needs of users. Intelligent management of e-commerce supply chain is an integrated management idea and method, which integrates the planning, organization, coordination and control of logistics, information flow, capital flow, value-added flow, business flow, and trading partnership in the linear and nonlinear optimization models. Through supply chain management, the enterprises can improve operational efficiency, improve asset utilization, shorten the total order cycle, reduce transaction costs, enhance customer service, improve response speed, penetrate new markets, obtain higher return on assets, and enhance their competitiveness.

With the widespread application of e-commerce, information and funds are transparently, quickly, and accurately transferred between member nodes of the supply chain through the Internet, which greatly improves the information flow management and capital flow management in supply chain management. Breakthrough to change the traditional scope of raw material procurement, production, sales, and services to meet the new requirements of high quality, high flexibility, and low cost imposed by the market on corporate production management in the new competitive environment is the inevitable requirement of the supply chain management model in the e-commerce environment. The realization of the e-commerce supply chain management process optimization is based on the integration and sharing of information. The efficient operation of the supply chain requires the enterprises of each node to give high-quality information data and fast information flow [19]. The e-commerce supply chain information integration and sharing platform can achieve unified standards for internal and external information, interoperable, seamless docking, integration, analysis, and sharing so that each node company in the supply chain can perceive information in a short time. At the same time, it is convenient for the enterprises of each node to grasp the production progress of the product and the operation of the supply chain in time. Based on the integration of internal and external mass information and the direction of the wind, it promotes the orderly interaction of internal and external management systems and the coordinated development of business.

\section{Simulation Experiment Analysis}

5.1. Simulation Experiment Design. According to the IoTbased e-commerce supply chain linear or nonlinear optimization model, the importance order of each influencing factor from least important to most important is circulation sociality, circulation convenience, circulation timeliness, surplus level, circulation quality, and circulation cost.

It is assumed that the selected e-commerce supply chain contains $n$ optimization processes; the hierarchical singleorder calculation of the above six influencing factors by the $i$ th process is as follows: 


\begin{tabular}{|l|l|l|l|l|}
\hline$a_{11}$ & $a_{12}$ & $\ldots$ & $a_{1 n-1}$ & $a_{1 n}$ \\
\hline$a_{21}$ & $a_{22}$ & $\ldots$ & $a_{24}$ & $a_{25}$ \\
\hline$P_{x 1}$ & $P_{x 2}$ & $\ldots$ & $P_{x n-1}$ & $P_{x n}$ \\
\hline$a_{n-11}$ & $a_{n-12}$ & $\ldots$ & $a_{n-1 n-1}$ & $a_{n-1 n}$ \\
\hline$a_{n 1}$ & $a_{n 2}$ & $\ldots$ & $a_{n n-1}$ & $a_{n n}$ \\
\hline
\end{tabular}

(a)

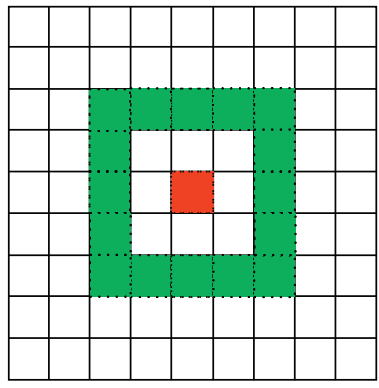

(c)

\begin{tabular}{|c|c|c|c|c|}
\hline$a_{11}$ & $a_{12}$ & $q_{x 1}$ & $a_{1 n-1}$ & $a_{1 n}$ \\
\hline$a_{21}$ & $a_{22}$ & $q_{x 2}$ & $a_{24}$ & $a_{25}$ \\
\hline$\ldots$ & $\ldots$ & $\ldots$ & $\ldots$ & $\ldots$ \\
\hline$a_{n-11}$ & $a_{n-12}$ & $q_{x n-1}$ & $a_{n-1 n-1}$ & $a_{n-1 n}$ \\
\hline$a_{n 1}$ & $a_{n 2}$ & $q_{x n}$ & $a_{n n-1}$ & $a_{n n}$ \\
\hline
\end{tabular}

(b)

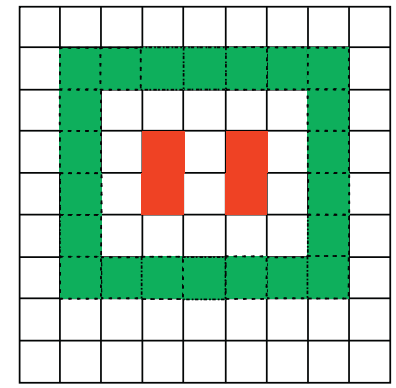

(d)

FIGURE 4: IoT-based node distribution of logistics supply chain with horizontal (a, c) and vertical integration modes (b, d).

$$
M_{i j}=\sum A_{i j}(i, j=1,2,3,4,5,6) .
$$

According to the judgment matrix of the supply chain optimization process, it can be clearly obtained that the optimization coefficients $\left(O_{i}\right)$ are $O_{1}=15.34, O_{2}=13.66$, $\mathrm{O}_{3}=17.19, \mathrm{O}_{4}=14.03, \mathrm{O}_{5}=11.35$, and $\mathrm{O}_{6}=12.89$.

The optimization weighting factor $s_{i}$ is calculated by $s_{i}=\sum_{i, j=1}^{6}\left(A_{i j} O_{i} / M_{i j}\right)$, and then the results are $s_{1}=0.54$, $s_{2}=0.23, s_{3}=0.48, s_{4}=0.56, s_{5}=0.44$, and $s_{6}=0.29$.

The optimization quality $Q_{i}$ is calculated by $Q_{i}=O_{i} / W_{i}$, and then the values were calculated as $Q_{1}=0.84, Q_{2}=0.91$, $Q_{3}=0.75, Q_{4}=0.87, Q_{5}=0.66$, and $Q_{6}=0.93$.

According to the supply chain before and after the optimization, each level is sorted separately from the particularity of the second-order matrix, and the weight proportion $\left(W_{1}\right)$ and priority $\left(W_{2}\right)$ of each matrix are calculated as follows. In $Q_{1}$, the proportion of $W_{1}$ is 0.31 and the proportion of $W_{2}$ is 0.25 . In $Q_{2}$, the proportion of $W_{1}$ is 0.58 and $W_{2}$ ratio is 0.42 . In $Q_{3}, W_{1}$ ratio is 0.19 and $W_{2}$ ratio is 0.85 . In $Q_{4}, W_{1}$ ratio is 0.56 and $W_{2}$ ratio is 0.63 . In $Q_{5}, W_{1}$ ratio is 0.37 and $W_{2}$ ratio is 0.94 . In $Q_{6}$, the $W_{1}$ ratio is 0.59 and $W_{2}$ ratio is 0.66 .

Finally, the consistency of the matrix is checked, and the supply chain optimization consistency parameter $f_{n}=$ 0.0537 under the condition of $n=6$, and the value is less than 0.1 , that is, it can pass the consistency check.

5.2. Result Analysis. To a certain extent, the structural level of the supply chain can reflect the cost and profit appreciation process of e-commerce products from demand forecasting, production, and processing to completion of sales. The more the layers in the supply chain structure, the more the number of different companies' value chains linked, the greater the cost, and the worse the economic benefits of the entire value chain in the integrated linear or nonlinear management models (Figure 5). Therefore, reducing the structural level of the e-commerce product supply chain and establishing dynamic cooperation relationships are important ways for enterprises to reduce bad costs and improve operating results. The optimization efficiency varies from 0.96 to 0.50 when the weighting factor equals 0.30 in the linear model while it varies from 0.88 to 0.61 in the nonlinear model. The low entry cost of virtual markets, as well as the uneven distribution of market information reformed by information overload and dynamic information flow, makes the information asymmetry between economic entities continue to exist within a certain range. In most cases, this sedimentary value is mainly manifested as the cost of invalid logistics and continues to be a defect in the overall economic benefits of the e-commerce product supply chain. All members in the supply chain should be a unified and harmonious division of labor and cooperation, while the characteristics of the traditional supply chain structure are relatively complex, the members are relatively stable, and the interdependence is strong and harmony between members of the supply chain in the linear and nonlinear optimization models.

Different from the previous concept of the operation level of e-commerce supply chain, as an intermediary variable, the mechanism of IoT application affecting enterprise performance is studied. Supply chain integration is used as an intermediary variable to study the mechanism of IoT application affecting enterprise performance. The intermediary role of supplier integration and customer integration can affect business performance. The IoT applications can affect e-commerce business performance through the full mediation role of supplier integration but only through the 


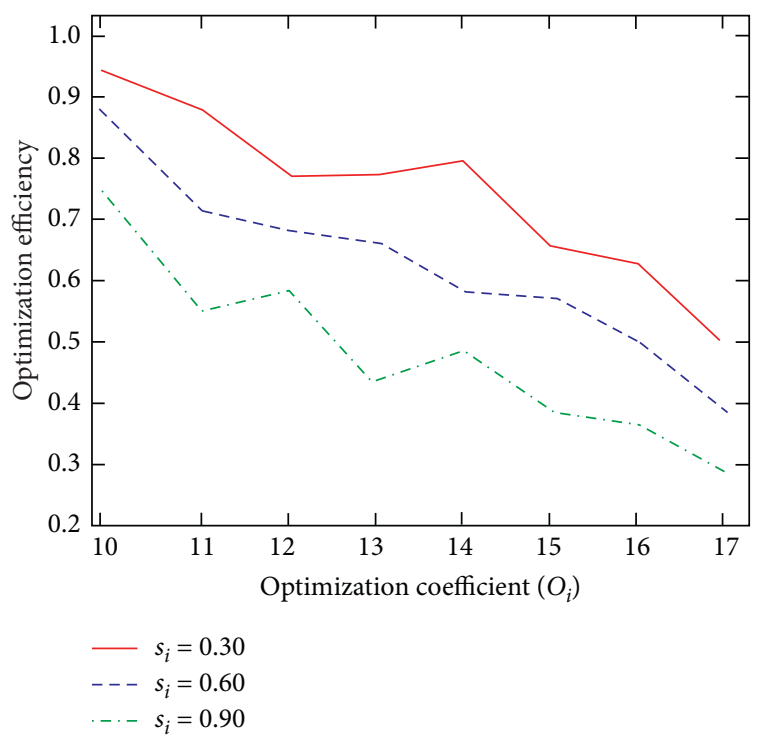

(a)

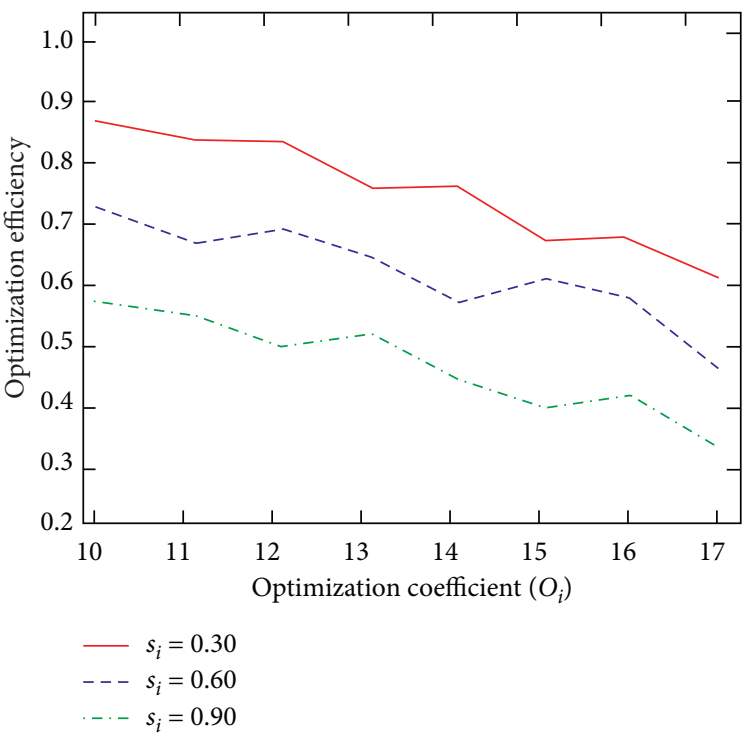

(b)

FIGURE 5: Relationship between optimization efficiency and coefficient with different weighting factors $\left(s_{i}\right)$ in the linear (a) and nonlinear (b) management model.

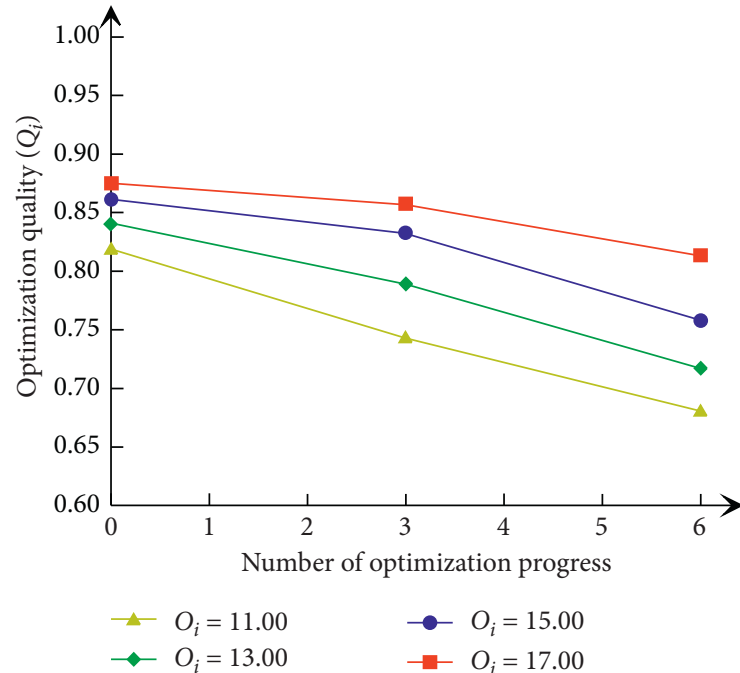

(a)

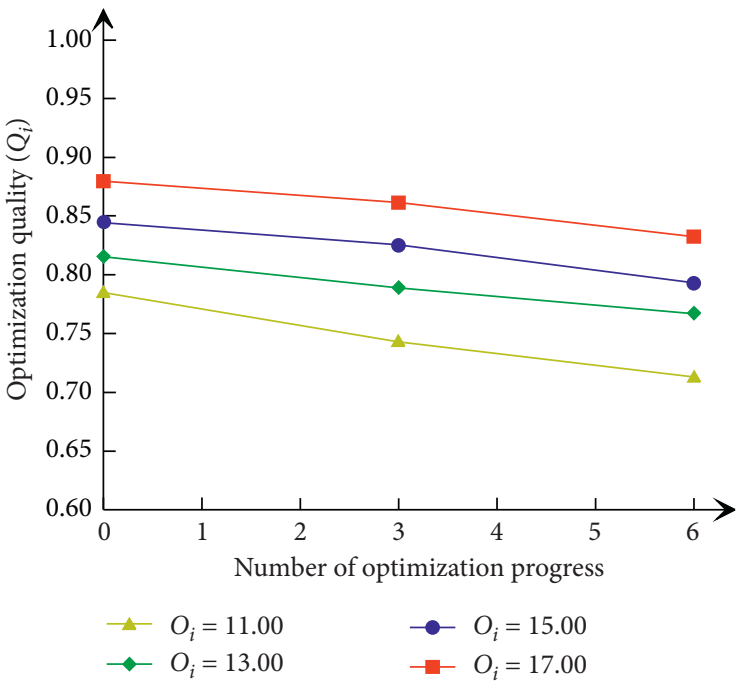

(b)

FIGURE 6: Relationship between optimization quality and the number of optimization progress with different optimization coefficients $\left(O_{i}\right)$ in the linear (a) and nonlinear management model (b).

partial mediation role of customer integration. The e-commerce can not only link the IoT with existing processes, products, or services but also the IoT with new processes, products, or services. In the process of IoT application, e-commerce companies should pay attention to the level of supply chain integration, especially supplier integration, because the two types of IoT applications can improve the performance of enterprises through the full mediation of supplier integration and the partial mediation of customer integration (Figure 6). The optimization quality changes from 0.87 to 0.84 when optimization coefficient equals 11.00 in the linear model while it changes from 0.87 to 0.85 in the nonlinear model. Therefore, the enterprises should increase investment in supplier and customer relationships, establish mechanisms for sharing information with suppliers and customers, actively coordinate conflicts with suppliers and customers, and promote joint resolution of problems with suppliers and customers in the linear and nonlinear optimization models, thereby enhancing the company's relationship with the level of supplier and customer integration and then the performance impact of IoT applications [20]. 


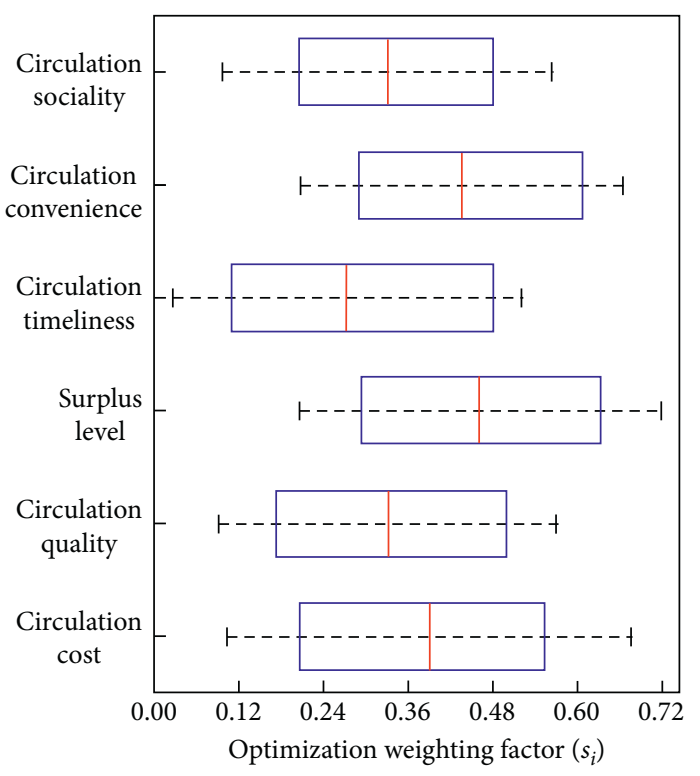

(a)

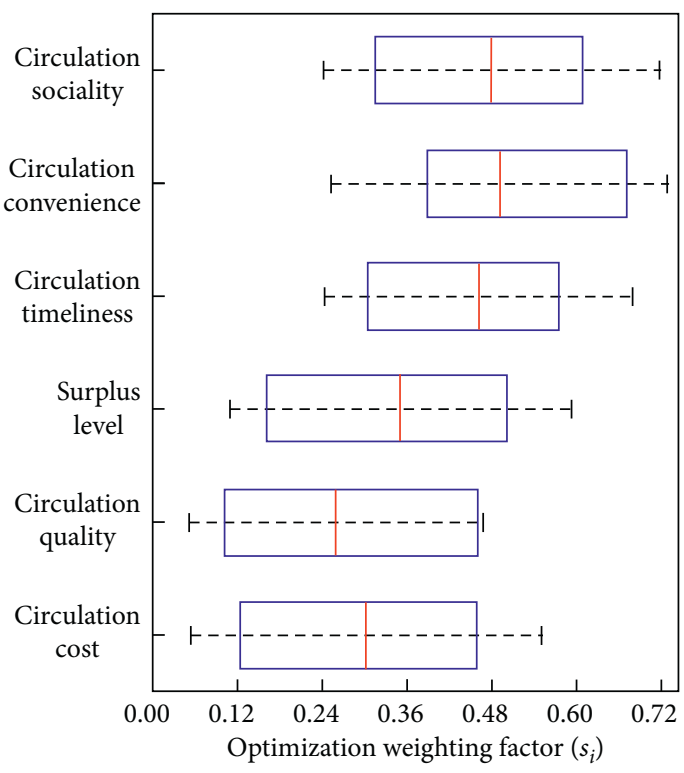

(b)

FIGURE 7: Optimization weighting factors $\left(s_{i}\right)$ of influential factors in IoT-based e-commerce supply chain with horizontal (a) and vertical (b) integration modes.

Cost optimization is the main way for enterprises to win market competition. The implementation of e-commercebased procurement supply chain management can effectively reduce the cost of global procurement for enterprises and make the procurement supply chain cost optimized. The optimization weighting factors of influential factors in IoT-based e-commerce supply chain with horizontal and vertical integration modes are shown in Figure 7 . The procurement management system implements procurement management based on the supplier's credit points to support enterprises to realize the supply control process in the supply chain environment. Through the timely and rapid update of information and integrated processing, it can achieve collaborative management of production and sales, shorten the manufacturing cycle, reduce customer waiting time, and improve customer satisfaction. The inventory management system uses the supplier's joint inventory management strategy to share the e-commerce enterprise's inventory information with the supplier to achieve supply integrated optimization of chain inventory and service level [21]. The management efficiency of the supply chain depends on the coordination between enterprises through information sharing. The basis of information sharing is to establish an integrated management information system to increase the supply chain members to obtain information timeliness and visibility to improve demand forecast accuracy [22]. In the IoT environment, e-commerce can give full play to the synergies of products, processes, and information, reduce loops and cycles, effectively avoid problems caused by information asymmetry through system construction, improve technology, and make the entire system and management construction of the process cover all aspects of information sharing requirements, which further improves the effect of application integration and standardizes and collects information in the supply chain.

\section{Conclusions}

This article expounded the research status and significance of e-commerce supply chain optimization, elaborated the development background, current status, and future challenges of the IoT technology, introduced the methods and principles of the node distribution model and constraint parameter analysis of logistics supply chain, constructed an IoT-based e-commerce supply chain model including competition and risk-control modules, performed the design of IoT-based e-commerce supply chain optimization, and discussed the solutions to procurement robustness optimization and management process optimization. The optimization efficiency varies from 0.96 to 0.50 when the weighting factor equals 0.30 in the linear model while it varies from 0.88 to 0.61 in the nonlinear model. The optimization quality changes from 0.87 to 0.84 when the optimization coefficient equals 11.00 in the linear model while it changes from 0.87 to 0.85 in the nonlinear model. With the support of IoT technology, the e-commerce procurement link requires long-term mutual benefit and close cooperation of information sharing among members of the supply chain, which is necessary to continuously improve the management level of suppliers and support a series of supplier management activities. The final simulation analysis showed that the proposed optimization model can effectively predict e-commerce product information in each stage of the supply chain; the IoT-based e-commerce supply chain optimization can enable each node company in the supply chain to improve the quality of information transmission and reduce the risk of information asymmetry in the process of e-commerce exchanges and can quickly and easily respond to the sudden changes of market and environment, thereby promoting them to cooperate with each other for 
establishing a supply chain network structure with closer business relationships, smoother logistics transportation, more reasonable benefit sharing, and stronger market competitiveness. The study results of this paper provide a certain reference for further research studies on the e-commerce supply chain optimization in the IoT environment.

\section{Data Availability}

The data used to support the findings of this study are available from the corresponding author upon request.

\section{Conflicts of Interest}

The author declares no known conflicts of interest or personal relationships that could have appeared to influence the work reported in this paper.

\section{Acknowledgments}

This work was supported by the Guangdong Province Natural Science Fund Project: Construction and Innovation of E-commerce Models by empirical study (no. S2013010011522) and Zhuhai Science and Technology Project: Research on the Development of Internet of Things industry in Zhuhai (no. 2011B030102006).

\section{References}

[1] M. Abdel-Basset, G. Manogaran, and M. Mohamed, "Internet of things (IoT) and its impact on supply chain: a framework for building smart, secure and efficient systems," Future Generation Computer Systems, vol. 86, pp. 614-628, 2018.

[2] E. Manavalan and K. Jayakrishna, "A review of internet of things (IoT) embedded sustainable supply chain for industry 4.0 requirements," Computers and Industrial Engineering, vol. 127, pp. 925-953, 2019.

[3] F. Caro and R. Sadr, "The internet of things (IoT) in retail: bridging supply and demand," Business Horizons, vol. 62, no. 1, pp. 47-54, 2019.

[4] A. Haddud, A. R. DeSouza, A. Khare, and H. Lee, "Examining potential benefits and challenges associated with the internet of things integration in supply chains," Journal of Manufacturing Technology Management, vol. 28, no. 8, pp. 1055-1085, 2017.

[5] Y. Zhang and J. Wen, "The IoT electric business model: using blockchain technology for the internet of things," Peer-to-Peer Networking and Applications, vol. 10, no. 4, pp. 983-994, 2017.

[6] O. Elijah, T. A. Rahman, I. Orikumhi, C. Y. Leow, and M. N. Hindia, "An overview of internet of things (IoT) and data analytics in agriculture: benefits and challenges," IEEE Internet of Things Journal, vol. 5, no. 5, pp. 3758-3773, 2018.

[7] X. Shang, R. Zhang, X. Zhu, and Q. Zhou, "Design theory, modelling and the application for the internet of things service," Enterprise Information Systems, vol. 10, no. 3, pp. 249-267, 2016.

[8] S. Liu, Y. Zhang, Y. Liu, L. Wang, and X. V. Wang, "An "internet of things" enabled dynamic optimization method for smart vehicles and logistics tasks," Journal of Cleaner Production, vol. 215, pp. 806-820, 2019.
[9] F. Javed, M. K. Afzal, M. Sharif, and B. S. Kim, "Internet of things (IoT) operating Systems support, networking technologies, applications, and challenges: a comparative review," IEEE Communications Surveys \& Tutorials, vol. 20, no. 3, pp. 2062-2100, 2018.

[10] P. Liu and S. P. Yi, "Pricing policies of green supply chain considering targeted advertising and product green degree in the big data environment," Journal of Cleaner Production, vol. 164, pp. 1614-1622, 2017.

[11] L. F. Hsu, "E-commerce model based on the internet of things," Advanced Science Letters, vol. 22, no. 10, pp. 3089-3091, 2016.

[12] S. S. Kamble, A. Gunasekaran, H. Parekh, and S. Joshi, "Modeling the internet of things adoption barriers in food retail supply chains," Journal of Retailing and Consumer Services, vol. 48, pp. 154-168, 2019.

[13] A. Musa and A. A. A. Dabo, "A review of RFID in supply chain management: 2000-2015," Global Journal of Flexible Systems Management, vol. 17, no. 2, pp. 189-228, 2016.

[14] B. D. Chung, S. I. Kim, and J. S. Lee, "Dynamic supply chain design and operations plan for connected smart factories with additive manufacturing," Applied Sciences, vol. 8, no. 4, p. 583, 2018.

[15] C. Liu, Y. Xiao, V. Javangula, Q. Hu, S. Wang, and X. Cheng, "NormaChain: a blockchain-based normalized autonomous transaction settlement system for IoT-based E-commerce," IEEE Internet of Things Journal, vol. 6, no. 3, pp. 4680-4693, 2018.

[16] S. Tiwari, H. M. Wee, and Y. Daryanto, "Big data analytics in supply chain management between 2010 and 2016: insights to industries," Computers \& Industrial Engineering, vol. 115, pp. 319-330, 2018.

[17] A. Boiko, V. Shendryk, and O. Boiko, "Information systems for supply chain management: uncertainties, risks and cyber security," Procedia Computer Science, vol. 149, pp. 65-70, 2019.

[18] Q. Tao, C. Gu, Z. Wang, J. Rocchio, W. Hu, and X. Yu, "Big data driven agricultural products supply chain management: a trustworthy scheduling optimization approach," IEEE Access, vol. 6, pp. 49990-50002, 2018.

[19] Y. Zhang, "Application of improved BP neural network based on e-commerce supply chain network data in the forecast of aquatic product export volume," Cognitive Systems Research, vol. 57, pp. 228-235, 2019.

[20] M. Zhang, G. Q. Huang, S. X. Xu, and Z. Zhao, "Optimization based transportation service trading in $\mathrm{B} 2 \mathrm{~B}$ e-commerce logistics," Journal of Intelligent Manufacturing, vol. 30, no. 7, pp. 2603-2619, 2019.

[21] A. Saif and S. Elhedhli, "Cold supply chain design with environmental considerations: a simulation-optimization approach," European Journal of Operational Research, vol. 251, no. 1, pp. 274-287, 2016.

[22] J. Huang and J. Song, "Optimal inventory control with sequential online auction in agriculture supply chain: an agentbased simulation optimisation," International Journal of Production Research, vol. 56, no. 6, pp. 2322-2338, 2018. 